\title{
Pseudoacanthocephalus lutzi (Hamann, 1891) comb.n. (Acanthocephala: Echinorhynchidae) for Acanthocephalus lutzi (Hamann, 1891), parasite of South American amphibians
}

\author{
Nathalia J. Arredondo and Alicia A. Gil de Pertierra
}

Laboratorio de Helmintología, Facultad de Ciencias Exactas y Naturales, Universidad de Buenos Aires, Buenos Aires, Argentina

\begin{abstract}
Acanthocephalus lutzi (Hamann, 1891) is proposed to be transferred to the genus Pseudoacanthocephalus Petrochenko, 1956 based on the type material from Rhinella marina (L.) from Brazil and recently collected material from R. arenarum (Hensel) from Argentina. Pseudoacanthocephalus is characterised by the following features: a cylindrical trunk without spines, a cylindrical proboscis, testes in tandem, a compact cluster of cement glands, a nearly terminal male genital pore, a ventral and sub-terminal female genital pore, and egg without polar prolongations, containing a holoechinate acanthor. Pseudoacanthocephalus lutzi comb. $\mathrm{n}$. has a proboscis armature of 14-18 longitudinal rows of 5-8 hooks each, with all roots formed by a posteriorly directed longitudinal spatulate sheet having a central rib, and an inconspicuous sheet directed anteriorly; a variable number (4, 5 or 6$)$ of cement glands; a cerebral ganglion located near the base of the proboscis receptacle; digitiform to claviform lemnisci, as long as, or slightly shorter or slightly longer than the proboscis receptacle; a sigmoid-shaped posterior end in males; an egg with a conspicuous fibrillar coat; and one of the larval hooks more robust and different in shape than the others. Additionally, the type material of Acanthocephalus saopaulensis Smales, 2007 from Rhinella icterica (Spix) from Brazil and a paratype of A. caspanensis Fernández et Ibarra Vidal, 1992 from $R$. spinulosa (Wiegmann) from Chile were studied. Acanthocephalus saopaulensis is considered conspecific with $P$. lutzi and A. caspanensis is transferred to Pseudoacanthocephalus because it possesses all the characters of the genus mentioned above. The use of characters such as egg morphology and host ecology for distinguishing Acanthocephalus from Pseudoacanthocephalus is also discussed.
\end{abstract}

Key words: Acanthocephala, Echinorhynchidae, Acanthocephalus lutzi, Pseudoacanthocephalus, Rhinella, amphibians, Argentina

Hamann (1891) described Echinorhynchus lutzi from Bufo agua Latreille [syn. B. marinus Gravenhorst; now Rhinella marina (L.) (see Frost et al. 2006, Frost 2009)] from Brazil. Later, Meyer (1932) transferred E. lutzi to Acanthocephalus Koelreuther, 1771 and it was accepted by Hartwich (1956), Yamaguti (1963), Golvan (1969) and Amin (1985).

The genus Acanthocephalus currently includes parasites of fishes, amphibians and reptiles, whereas Pseudoacanthocephalus Petrochenko, 1956 includes only parasites of amphibians and reptiles. Pseudoacanthocephalus is a valid genus accepted and reallocated by Golvan (1969, 1994) and Amin (1985) to the Echinorhynchidae Cobbold, 1879.

The identification and assignment of taxa parasitizing amphibians to the genera Acanthocephalus and Pseudoacanthocephalus have been subject of discussion and controversy (Golvan 1969, 1994, Amin 1985, Smales 2005, 2007, Amin et al. 2008).
In South America, A. lutzi has been recorded several times in amphibians and reptiles in Uruguay (Cordero 1933), Peru (Tantaleán 1976, Tantaleán et al. 2005), Argentina (Lajmanovich and Martínez de Ferrato 1995, Gutiérrez et al. 2005) and Brazil and Paraguay (Smales 2007). Since the original description, its taxonomic position is controversial because several authors found differences, principally in the number of cement glands (Meyer 1932, Hartwich 1956, Yamaguti 1963, Golvan 1969, 1994, Lajmanovich and Martínez de Ferrato 1995, Smales 2007).

During a parasitological survey of amphibians in Argentina, numerous acanthocephalans were collected from Rhinella arenarum (Hensel). These worms were previously assigned to A. lutzi from Argentina by Lajmanovich and Martínez de Ferrato (1995). The taxonomic position of $A$. lutzi was re-evaluated based on recently collected material from Argentina, paratypes from $R$. marina (L.) from Brazil, paratypes of Acanthocephalus saopaulensis Smales, 2007 from R. icterica (Spix) from Brazil, and

Address for correspondence: N.J. Arredondo, Laboratorio de Helmintología, Departamento de Biodiversidad y Biología Experimental, Facultad de Ciencias Exactas y Naturales, Pabellón II, $4^{\circ}$ Piso, Ciudad Universitaria, Int. Güiraldes 2160, Universidad de Buenos Aires, C1428EGA - Buenos Aires, Argentina. Phone: ++54 11 4576-3349; Fax: ++54 11 4576-3384; E-mail: arredondonj@bg.fcen.uba.ar 
a paratype of Acanthocephalus caspanensis Fernandez et Ibarra Vidal, 1992 from $R$. spinulosa (Wiegmann) from Chile. The characters considered were clustered cement glands and their number, the morphology of the egg and the position of the genital pores. The terrestrial habitat of the hosts is discussed.

\section{MATERIALS AND METHODS}

Sixty-nine specimens of the toad $R$. arenarum were examined for intestinal parasites. The amphibians were collected

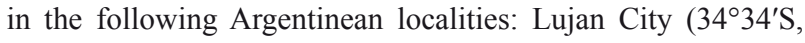
$59^{\circ} 06^{\prime} \mathrm{W}$ ), Buenos Aires Province in June 2004 and from August to December 2004; and in the campus at the University of Buenos Aires $\left(34^{\circ} 32^{\prime} \mathrm{S}, 58^{\circ} 26^{\prime} \mathrm{W}\right)$, Buenos Aires City in June 2004, November 2007, June 2008 and February 2009, Argentina.

Acanthocephalans found in the intestine were isolated and relaxed for a few hours or overnight in $0.9 \% \mathrm{NaCl}$. Then they were fixed in $4 \%$ formaldehyde solution and stored in $70 \%$ ethanol. Some worms were stained with Langeron's alcoholic chlorhydric carmine (Langeron 1949), differentiated in acid ethanol, dehydrated through a gradual ethanol series, cleared in beechwood creosote and finally mounted in Canada balsam. Other specimens were cleared in Amman's lactophenol or in beechwood creosote, which allows the rotation of the specimen during examination. Spontaneously laid eggs were fixed in $4 \%$ formaldehyde solution and examined in distilled water for drawing. Hand-cut cross-sections from two males were stained with Langeron's alcoholic chlorhydric carmine.

Specimens from Argentina were deposited in the Parasitological Collection of the Museo Argentino de Ciencias Naturales "Bernardino Rivadavia", Buenos Aires, Argentina (MACN-Pa) and in the Helminthological Collection of the Museum für Naturkunde, Zentralinstitut der Humboldt-Universität, Berlin, Germany (ZMB). The following material was also studied: type material of Acanthocephalus lutzi Hamann, 1891 from $R$. marina from Brazil (= TM throughout description), deposited in the Helminthological Collection of the Museum für Naturkunde, Zentralinstitut der Humboldt-Universität, Berlin, Germany (ZMB Vermes E4408, one male paratype, five male and five female paratypes preserved in $70 \%$ ethanol); type material of $A$. caspanensis from $R$. spinulosa from Chile, deposited in the Museo Zoológico de la Universidad de Concepción, Chile (MZUC 12935, one male paratype); and type material of A. saopaulensis from $R$. icterica from Brazil, deposited in the Natural History Museum, Geneva, Switzerland (MHNG INVE 38665,39685 , three males, four females, parts of two females, paratypes).

Seven specimens of $A$. lutzi from $R$. arenarum from Argentina preserved in $70 \%$ ethanol were prepared for scanning electron microscopy (SEM) as follows: post-fixed in $1 \%$ osmium tetroxide, dried with hexamethyldisilazane (Riedel-De Haën ${ }^{\circledR}$ ), mounted on stubs with adhesive tape, sputter coated with gold in a Thermo VG Scientific Polaron SC 7630 and examined with a Philips XL 30 SEM.

Measurements include the range followed by the mean in parentheses, standard deviation, total number of measurements (n) and the coefficient of variability (CV). All measurements are given in micrometres, unless otherwise stated. Illustrations were made with the aid of a camera lucida on a Zeiss Axioskop microscope.
Prevalence, mean intensity of infection and mean abundance were calculated according to Bush et al. (1997). The nomenclature for the embryonic membranes follows Marchand (1984) and Nikishin (2001) (E1-E4 membranes interspersed by fluid granular spaces).

\section{RESULTS}

Pseudoacanthocephalus lutzi (Hamann, 1891) comb. n. Figs. 1-4

Syns.: Echinorhynchus lutzi Hamann, 1891; Acanthocephalus saopaulensis Smales, 2007.

Description (based on new and type material): Palaeacanthocephala, Echinorhynchidae. Trunk and all shared structures larger in females than in males. Trunk cylindrical without spines. Proboscis cylindrical, with 14-18 (usually 15-16) $\mathrm{TM}=15$ longitudinal and regularly alternating rows of 5 to 7 (usually 5 to 6 ) $\mathrm{TM}=6-8$ hooks each. Hook length increases from apex to middle part of proboscis, then, decreases slightly or not towards base. All hooks rooted, formed by a posteriorly directed longitudinal spatulate sheet having a central rib, and an inconspicuous sheet directed anteriorly. Neck, broader at base. Proboscis receptacle cylindrical, double-walled with cellular elements associated with retractor muscles just exterior to its posterior tip. Cerebral ganglion near base of proboscis receptacle. Proboscis retractor muscles inserted at base of proboscis receptacle and at anterior third of the trunk. Lemnisci digitiform to claviform, as long as, or slightly shorter or slightly longer than proboscis receptacle. Female genital pore ventral, sub-terminal. Posterior end of male sigmoid-shaped. Male genital pore nearly terminal.

Male (based on 36 newly collected mature specimens and 6 type specimens): Trunk 4-8.8 $\mathrm{mm}(6.2 \pm 1.2 \mathrm{~mm}$, $\mathrm{n}=36, \mathrm{CV}=19 \%) \mathrm{TM}=8.2-12 \mathrm{~mm}(9.9 \mathrm{~mm}, \mathrm{n}=6)$ long, $0.6-1.6 \mathrm{~mm}(1.1 \pm 0.3 \mathrm{~mm}, \mathrm{CV}=23 \%) \mathrm{TM}=1.3$ $1.8 \mathrm{~mm}(1.6 \mathrm{~mm})$ wide. Proboscis, 350-560 (410 \pm 50 , $\mathrm{n}=25, \mathrm{CV}=12 \%) \mathrm{TM}=670(\mathrm{n}=1)$ long, $170-370$ $(240 \pm 47, \mathrm{CV}=20 \%) \mathrm{TM}=320$ wide, with $14-18$ $(16 \pm 1, \mathrm{n}=25, \mathrm{CV}=8 \%) \mathrm{TM}=15(\mathrm{n}=1)$ hook rows (Figs. 1B, 3A, 4A), each with 5-7 (usually 5-6) TM =6-7 $(\mathrm{n}=1)$ hooks each. Proboscis hook length from anterior: I 54-83 (68, $\mathrm{n}=8) \mathrm{TM}=55-90(70, \mathrm{n}=4)$, II 75-88 (91, $\mathrm{n}=12) \mathrm{TM}=95(\mathrm{n}=1)$, III 75-88 (81, $\mathrm{n}=12) \mathrm{TM}=98$ $113(105, \mathrm{n}=5)$, IV $78-90(82, \mathrm{n}=12) \mathrm{TM}=100-113$ $(105, \mathrm{n}=5), \mathrm{V} 65-95(81, \mathrm{n}=10) \mathrm{TM}=103-113(108$, $\mathrm{n}=7)$, VI 60-80 (73, $\mathrm{n}=6) \mathrm{TM}=100-118(109, \mathrm{n}=7)$, VII TM $=80-118(109, \mathrm{n}=7)$. Hook root length from anterior: I 42-60 (55, $\mathrm{n}=8) \mathrm{TM}=43-70(56, \mathrm{n}=5)$, II 48-65 (58, $\mathrm{n}=8) \mathrm{TM}=43-75(68, \mathrm{n}=7)$, III 50-68 $(62, \mathrm{n}=8) \mathrm{TM}=68-75(74, \mathrm{n}=7)$, IV $58-70(65, \mathrm{n}=6)$ $\mathrm{TM}=75-78(75, \mathrm{n}=7), \mathrm{V} 45-60(51, \mathrm{n}=5) \mathrm{TM}=73-80$ $(75, \mathrm{n}=7)$, VI 40-62 (49, $\mathrm{n}=3) \mathrm{TM}=75-83(77, \mathrm{n}=7)$, VII TM $=50-78(67, \mathrm{n}=7)$. Neck 120-220 $(155 \pm 30$, $\mathrm{n}=19, \mathrm{CV}=20 \%) \mathrm{TM}=170(\mathrm{n}=1)$ long. Proboscis receptacle $550-1,000 \quad(810 \pm 120, \mathrm{n}=31, \mathrm{CV}=15 \%)$ 

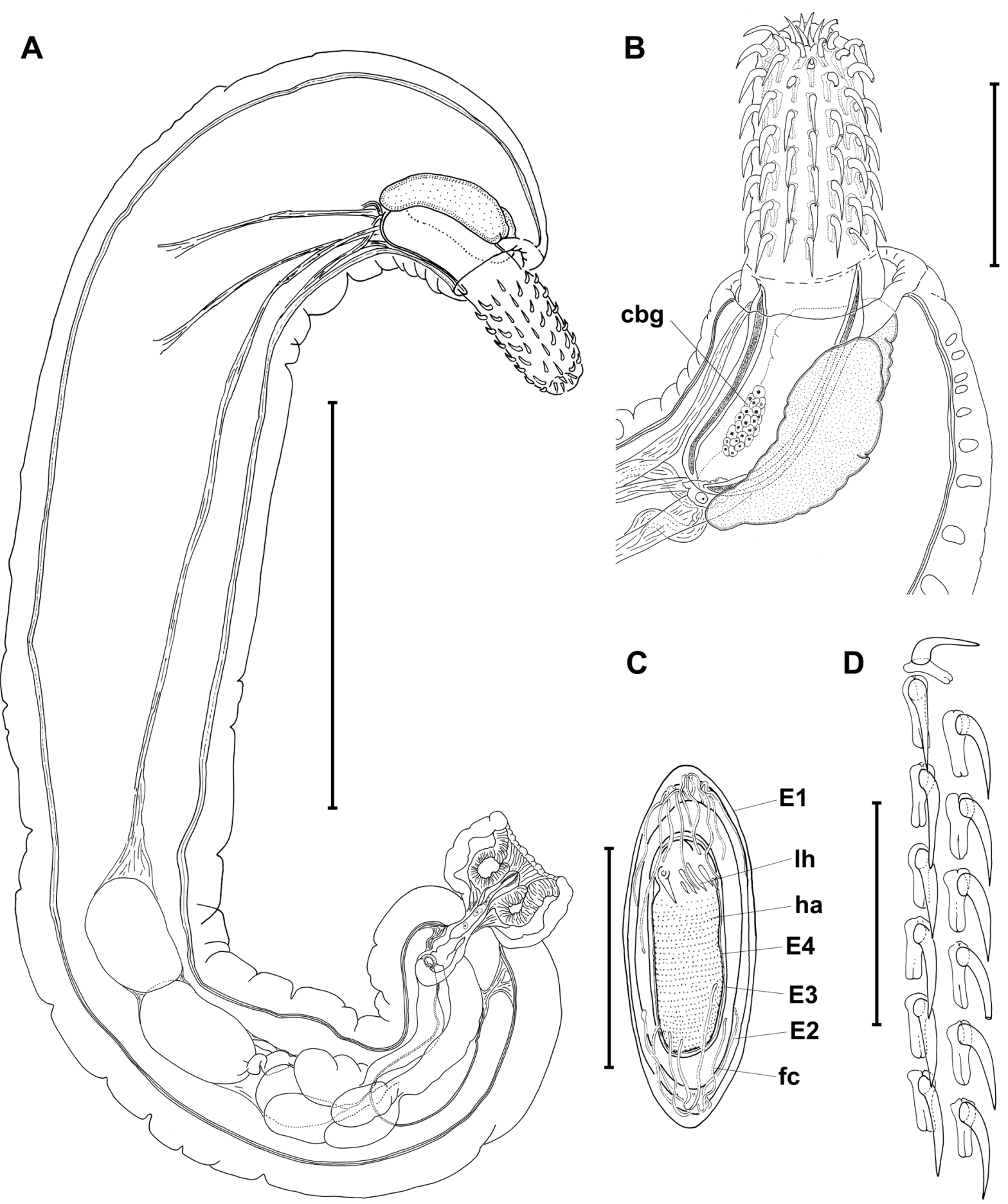

Fig. 1. Pseudoacanthocephalus lutzi (Hamann, 1891) comb. n., paratypes (ZMB Vermes E4408) from Rhinella marina. A - lateral view of a complete male specimen; B - detail of proboscis and anterior part of male trunk; C - morphology of egg; $\mathbf{D}$ - detail of hook rows showing roots in female. Abbreviations: cbg - cerebral ganglion; E1 - first envelope; E2 - second envelope; E3 - third envelope; $\mathrm{E} 4$ - fourth envelope adhered to holoechinate acanthor; fc - fibrillar coat; ha - holoechinate acanthor; lh - larval hooks. Scale bars: $\mathrm{A}=2 \mathrm{~mm} ; \mathrm{B}=500 \mu \mathrm{m} ; \mathrm{C}=50 \mu \mathrm{m} ; \mathrm{D}=250 \mu \mathrm{m}$. 
$\mathrm{TM}=700-860 \quad(800, \mathrm{n}=4) \quad$ long, $180-450 \quad(320 \pm 70$, $\mathrm{CV}=21 \%) \quad \mathrm{TM}=290-400 \quad$ (355) wide, occupying $10-18 \% \quad(13 \pm 2 \%, \mathrm{n}=31, \quad \mathrm{CV}=15 \%) \quad \mathrm{TM}=7-10 \%$ $(8 \pm 1 \%, n=4)$ of total length; cerebral ganglion 110-275 $(190 \pm 40, \mathrm{n}=19, \mathrm{CV}=22 \%) \mathrm{TM}=200(\mathrm{n}=1)$ long, 80-170 (125 $\pm 30, \mathrm{CV}=23 \%) \mathrm{TM}=100$ wide (Fig. 1B). Lemnisci $650-1,260(900 \pm 150, \mathrm{n}=59, \mathrm{CV}=17 \%)$ $\mathrm{TM}=480-960 \quad(680, \mathrm{n}=6)$ long, 100-520 (240 \pm 95 , $\mathrm{CV}=42 \%) \mathrm{TM}=200-310$ (280) wide. Testes ovoid, in tandem, contiguous but occasionally slightly overlapping (Figs. 1A, 2D, F); anterior testis 460-1,030 (670 \pm 155 , $\mathrm{n}=30, \mathrm{CV}=23 \%) \mathrm{TM}=580-860(715, \mathrm{n}=4)$ long, 260 $710(415 \pm 115, \mathrm{CV}=28 \%) \mathrm{TM}=390-690$ (530) wide; posterior testis $440-1,100(665 \pm 170, \mathrm{n}=30, \mathrm{CV}=26 \%)$ $\mathrm{TM}=650-830(745, \mathrm{n}=4)$ long, 260-670 (405 \pm 105 , $\mathrm{CV}=26 \%) \mathrm{TM}=380-650$ (545) wide. Two monorchid males out of $36(6 \%)$ examined, with testis size larger than mean (830 and 910 long). Cement glands in compact cluster, pyriform, multinucleated, variable in number $5(43 \%, \mathrm{n}=13) \mathrm{TM}=60 \%(\mathrm{n}=3)$ (Figs. 1A, 2F, G), $6(37 \%, n=11) \mathrm{TM}=20 \%(\mathrm{n}=1)($ Fig. $2 \mathrm{D})$, or $4(20 \%$, $\mathrm{n}=6) \mathrm{TM}=20 \%(\mathrm{n}=1) ; 225-850(475 \pm 130, \mathrm{n}=153$, $\mathrm{CV}=27 \%) \mathrm{TM}=375-650(525 \pm 95, \mathrm{n}=21, \mathrm{CV}=18 \%)$ long, $100-465 \quad(235 \pm 85, \mathrm{CV}=36 \%) \mathrm{TM}=175-530$ $(340 \pm 95, \mathrm{CV}=28 \%)$ wide, with 2 posterior cement reservoirs, 375-620 $(500, \mathrm{n}=4) \mathrm{TM}=650-950(\mathrm{n}=2)$ long, 120-175 (140) TM = 140-150 wide (Figs. 1A, 2D, F, G). Saefftigen's pouch, 340-1,320 (865 $\pm 245, \mathrm{n}=31$, $\mathrm{CV}=28 \%) \mathrm{TM}=1,070-1,480(1,213, \mathrm{n}=4)$ long, 200 $380(275 \pm 50, \mathrm{CV}=18 \%) \mathrm{TM}=345-420$ (390) wide. Penis, 60-185 (125 $\pm 30, \mathrm{n}=30, \mathrm{CV}=23 \%) \mathrm{TM}=125$ $(\mathrm{n}=1)$ long, $50-115(85 \pm 15, \mathrm{CV}=19 \%) \mathrm{TM}=90$ wide. Bursa with papillae, 460-660 (570, $\mathrm{n}=4) \mathrm{TM}=440$ ( $\mathrm{n}=1$ ) long, 430-750 (595) TM = 695 wide, with 2 bursal pockets, $110-250(160, n=5) T M=140-250(n=3)$ in diameter (Figs. 1A, 2D, 3E, F). Whole reproductive system post-equatorial. Reproductive system length $1.4-4.4 \mathrm{~mm}(3 \pm 1 \mathrm{~mm}, \mathrm{n}=32, \mathrm{CV}=24 \%) \mathrm{TM}=3.3$ $4.5 \mathrm{~mm}(4 \mathrm{~mm}, \mathrm{n}=4)$, occupying $23-59 \% \quad(47 \pm 7 \%$, $\mathrm{n}=32, \mathrm{CV}=15 \%) \mathrm{TM}=34-52 \%(41 \%, \mathrm{n}=4)$ of total length. Posterior end sigmoid-shaped. Genital pore nearly terminal (Figs. 1A, 2D, 3E).

Female (based on 35 newly collected mature or gravid specimens and 5 type specimens): Trunk cylindrical $7-21 \mathrm{~mm} \quad(11 \pm 3 \mathrm{~mm}, \mathrm{n}=35, \quad \mathrm{CV}=28 \%) \quad \mathrm{TM}=14$ $20 \mathrm{~mm}(16 \mathrm{~mm}, \mathrm{n}=5)$ long, 0.7-2 mm (1.5 $\pm 0.3 \mathrm{~mm}$, $\mathrm{CV}=25 \%) \mathrm{TM}=1.5-2 \mathrm{~mm}(1.5 \mathrm{~mm})$ wide. Proboscis $400-640(535 \pm 64, \mathrm{n}=16, \mathrm{CV}=12 \%) \mathrm{TM}=740-840$ $(\mathrm{n}=2)$ long, 220-430 (310 $\pm 55, \mathrm{CV}=17 \%) \mathrm{TM}=290$ 350 wide, with 14-18 $(16 \pm 1, \mathrm{n}=16, \mathrm{CV}=7 \%) \mathrm{TM}=15$ $(\mathrm{n}=1)$ hook rows, each with 5-7 (usually 6) $\mathrm{TM}=6-8$ hooks (Figs. 1D, 2B, C, 3B). Proboscis hook length from anterior: I $67-100(86 \pm 12, \mathrm{n}=20, \mathrm{CV}=16 \%) \mathrm{TM}=65$ $100(80, \mathrm{n}=3)$, II $68-109(92 \pm 9, \mathrm{n}=20, \mathrm{CV}=9 \%)$ $\mathrm{TM}=65-100 \quad(85, \mathrm{n}=6)$, III $80-113 \quad(98 \pm 8, \mathrm{n}=20$, $\mathrm{CV}=10 \%) \mathrm{TM}=85-105(96, \mathrm{n}=6), \operatorname{IV} 84-115(100 \pm 7$, $\mathrm{n}=20, \mathrm{CV}=10 \%) \mathrm{TM}=85-110(99, \mathrm{n}=6), \mathrm{V}$ 80-105 $(96 \pm 6, \mathrm{n}=18, \mathrm{CV}=9 \%) \mathrm{TM}=78-100(90, \mathrm{n}=6), \mathrm{VI}$ $75-105(90 \pm 8, \mathrm{n}=16, \mathrm{CV}=8 \%) \mathrm{TM}=93-110(100$, $\mathrm{n}=6)$, VII 85-90 (88, $\mathrm{n}=2) \mathrm{TM}=100-115(109, \mathrm{n}=5)$, VIII TM $=120(120, n=2)$. Hook root length from anterior I 50-72 $(65, \mathrm{n}=10) \mathrm{TM}=57-85(65, \mathrm{n}=4)$, II 56$70(67, \mathrm{n}=10) \mathrm{TM}=60-75(70, \mathrm{n}=4)$, III 65-90 (70, $\mathrm{n}=10) \mathrm{TM}=62-75(72, \mathrm{n}=4)$, IV 67-92 $(74, \mathrm{n}=12)$ $\mathrm{TM}=65-75(70, \mathrm{n}=4), \mathrm{V} 65-92(75, \mathrm{n}=10) \mathrm{TM}=70$ $80(75, \mathrm{n}=4)$, VI 68-90 (74, $\mathrm{n}=8) \mathrm{TM}=68-85(72$, $\mathrm{n}=5)$, VII 48-65 (55, n=6) TM=60-85 (70, $\mathrm{n}=4)$, VIII TM $=65-75(70, \mathrm{n}=2)$. Neck 100-340 $(165, \mathrm{n}=13)$ $\mathrm{TM}=320(\mathrm{n}=1)$ long. Proboscis receptacle 710-1,560 $(930 \pm 150, \mathrm{n}=33, \mathrm{CV}=16 \%) \mathrm{TM}=770-1,000$ (890, $\mathrm{n}=5)$ long, $270-500(395 \pm 60, \mathrm{CV}=15 \%) \mathrm{TM}=320$ 420 (365) wide, occupying 6-10\% (8\%) TM $=4-7 \%$ (6\%) of total length; cerebral ganglion 125-255 (180 \pm 35 , $\mathrm{n}=24, \mathrm{CV}=19 \%)$ long, 75-210 (129 $\pm 38, \mathrm{CV}=29 \%)$ wide (Fig. 2B). Lemnisci 380-1,780 $\quad(1,020 \pm 260$, $\mathrm{n}=64, \mathrm{CV}=26 \%) \mathrm{TM}=670-970 \quad(815, \mathrm{n}=6) \quad$ long, $110-480 \quad(285 \pm 80, \mathrm{CV}=29 \%) \quad \mathrm{TM}=270-440 \quad(345)$ wide. Uterine bell 310-700 $(430 \pm 90, \mathrm{n}=32, \mathrm{CV}=21 \%)$ $\mathrm{TM}=390-550 \quad(455,=4) \quad$ long, $115-220 \quad(165 \pm 25$, $\mathrm{CV}=16 \%) \mathrm{TM}=140-190$ (160) wide; uterus 135-375 $(240 \pm 70, \quad \mathrm{n}=32, \quad \mathrm{CV}=30 \%) \quad \mathrm{TM}=350-530 \quad(430$, $\mathrm{n}=4)$ long, $60-130(90 \pm 15, \mathrm{CV}=18 \%) \mathrm{TM}=80-110$ (95) wide; vagina $260-550(390 \pm 70, \mathrm{n}=32, \mathrm{CV}=18 \%)$ $\mathrm{TM}=495-600 \quad(550, \mathrm{n}=4)$ long, 100-200 (135 \pm 20 , $\mathrm{CV}=13 \%) \mathrm{TM}=140-200$ (165) wide, with a double muscular sphincter. Genital pore ventral, sub-terminal (Figs. 2A, 3D). Reproductive system length $0.7-1.6 \mathrm{~mm}$ $(1 \pm 0.2 \mathrm{~mm}, \quad \mathrm{n}=32, \quad \mathrm{CV}=18 \%) \quad \mathrm{TM}=1.3-1.6 \mathrm{~mm}$ (1.4 mm, $\mathrm{n}=4)$, occupying $8-13 \%(10 \pm 1 \%, \mathrm{CV}=13 \%)$ $\mathrm{TM}=7-10 \%(9 \%)$ of total length. Mature eggs elliptical with four envelopes; first envelope (E1) 54-88 (77 \pm 8 , $\mathrm{n}=34, \mathrm{CV}=11 \%) \mathrm{TM}=82-93(87, \mathrm{n}=8)$ long, 19-39 $(31 \pm 5, \mathrm{CV}=17 \%) \mathrm{TM}=29-42$ (37) wide; second envelope (E2), 50-76 (66 $\pm 6, \mathrm{n}=34, \mathrm{CV}=9 \%) \mathrm{TM}=70-80$ (76, $\mathrm{n}=8)$ long, 20-34 (27 $\pm 4, \mathrm{CV}=14 \%) \mathrm{TM}=26-38$ (33) wide with a conspicuous fibrillar coat; third envelope (E3) without polar prolongation, 46-63 $(54 \pm 4, \mathrm{n}=27$, $\mathrm{CV}=7 \%) \quad \mathrm{TM}=69-72 \quad(\mathrm{n}=2) \quad$ long, $18-28 \quad(23 \pm 3$, $\mathrm{CV}=14 \%$ ) $\mathrm{TM}=22-26$ wide; fourth envelope (E4) adhered to holoechinate acanthor 40-59 $(49 \pm 5, \mathrm{n}=31$, $\mathrm{CV}=10 \%) \mathrm{TM}=51-60(55, \mathrm{n}=8)$ long, $11-29(21 \pm 4$, $\mathrm{CV}=19 \%) \mathrm{TM}=15-26$ (21) wide, larval hooks 2-10 $(6 \pm 2, \mathrm{n}=40, \mathrm{CV}=35 \%) \mathrm{TM}=4-10(7, \mathrm{n}=10)$ long, with one hook more robust and different in shape 6-10 $(8 \pm 1, \mathrm{n}=24, \mathrm{CV}=12 \%) \mathrm{TM}=9-12(11, \mathrm{n}=7)$ long (Figs. 1C, 2E, 3C).

Type host: Rhinella marina (Linnaeus) (Anura: Bufonidae). Other hosts: Rhinella arenarum (Hensel) (syn. Bufo arenarum) and Rhinella icterica (Spix) (syn. Bufo ictericus) (Anura: Bufonidae).

Ty pe locality: Unknown, probably São Paulo (after Cordero 1933), Brazil. 
A

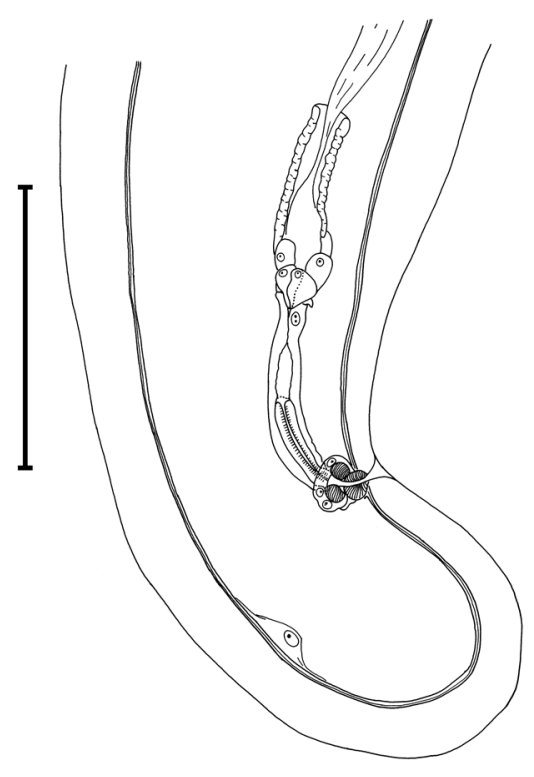

B

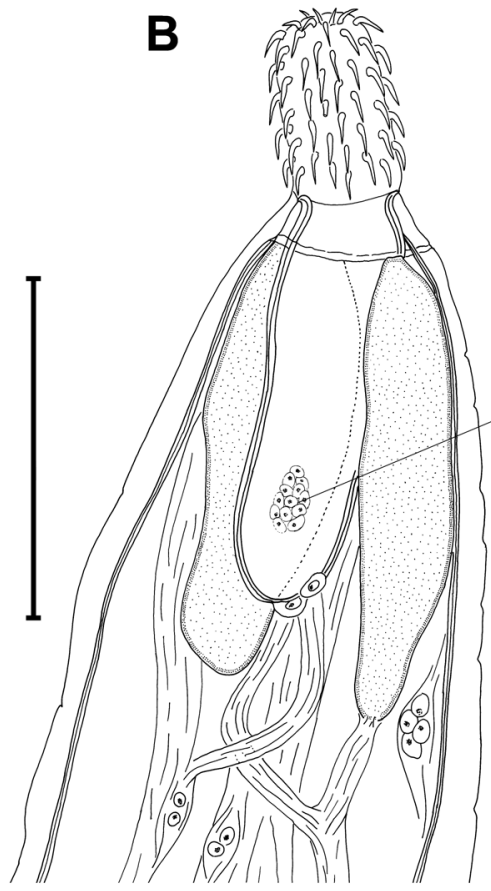

C

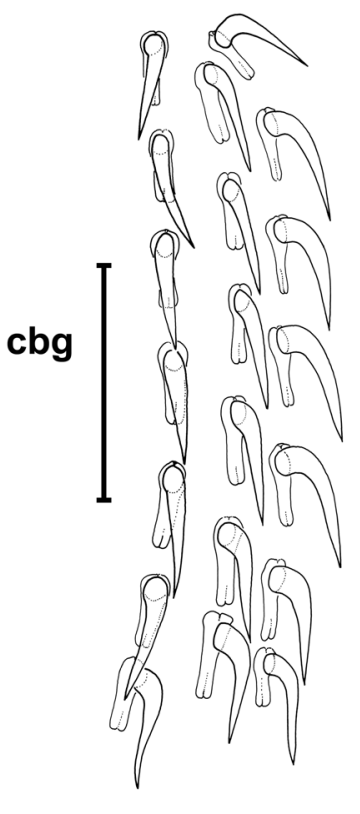

Ih
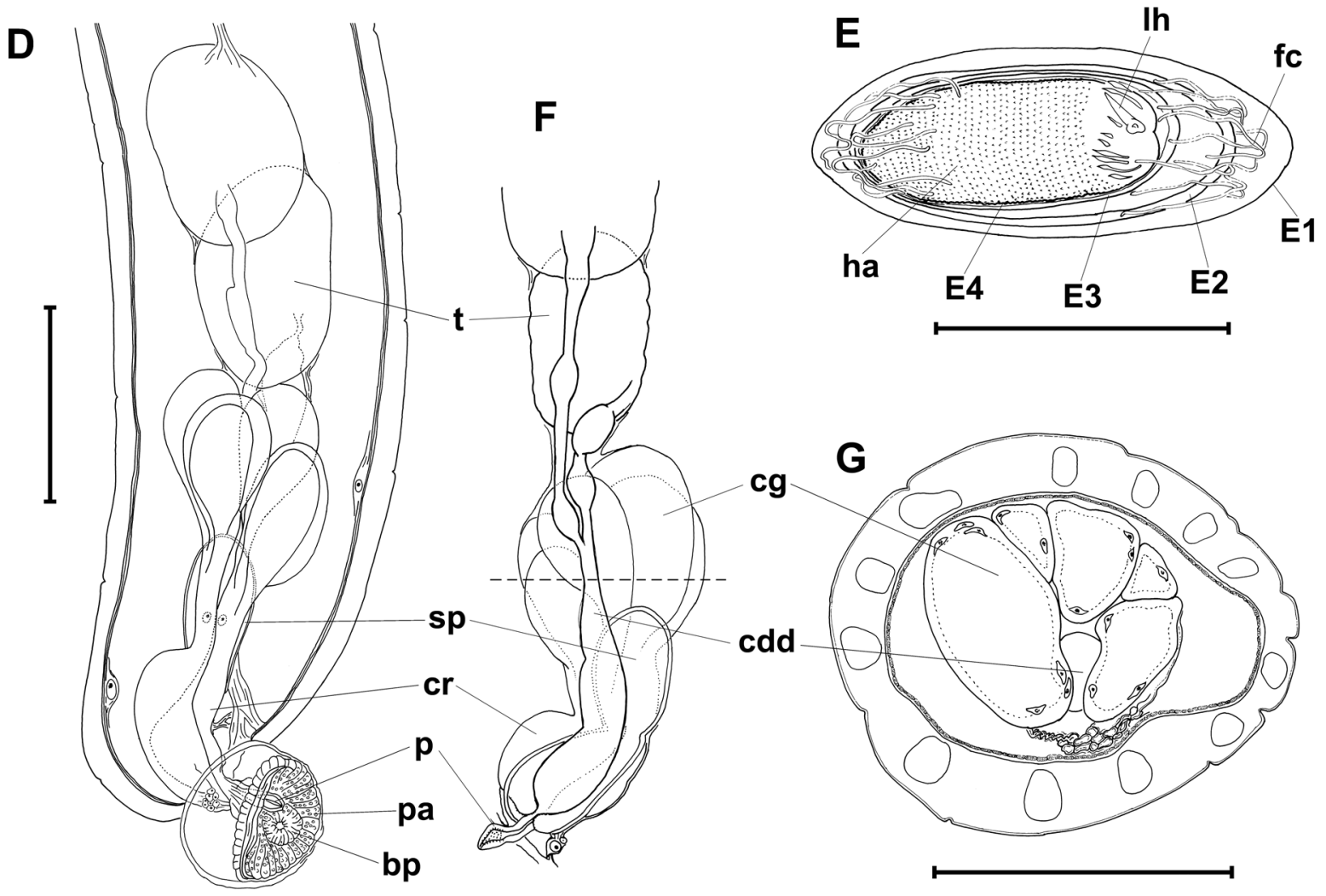

$\mathbf{F}$

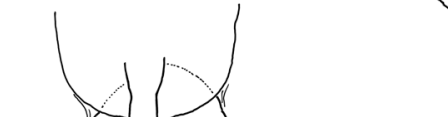

1

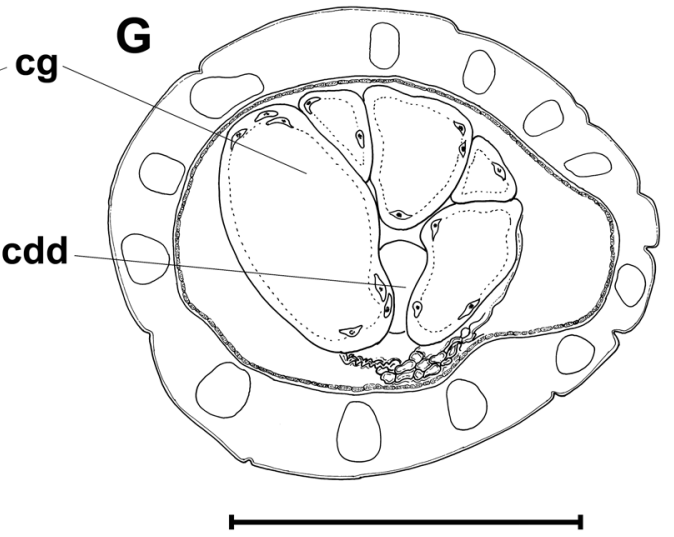

Fig. 2. Pseudoacanthocephalus lutzi (Hamann, 1891) comb. n. from Rhinella arenarum. A - lateral view of female reproductive system; $\mathbf{B}$ - anterior part of female trunk; $\mathbf{C}$ - detail of hook rows showing roots in female; $\mathbf{D}$ - lateral view of male reproductive system; $\mathbf{E}$ - morphology of egg; $\mathbf{F}$ - schematic view of male reproductive system showing the common deferent duct; $\mathbf{G}$ - transverse section at the cement gland level. Abbreviations: bp - bursal pockets; cbg - cerebral ganglion; cdd - common deferent duct; cg - cement glands; cr - cement reservoir; E1 - first envelope; E2 - second envelope; E3 - third envelope; E4 - fourth envelope adhered to holoechinate acanthor; fc - fibrillar coat; ha - holoechinate acanthor; lh - larval hooks; $\mathrm{p}$ - penis; pa - papillae; sp - Saefftigen's pouch; $\mathrm{t}$ - testis. Scale bars: $\mathrm{A}, \mathrm{B}, \mathrm{D}=1 \mathrm{~mm} ; \mathrm{C}=200 \mu \mathrm{m} ; \mathrm{E}=50 \mu \mathrm{m} ; \mathrm{G}=500 \mu \mathrm{m}$. 


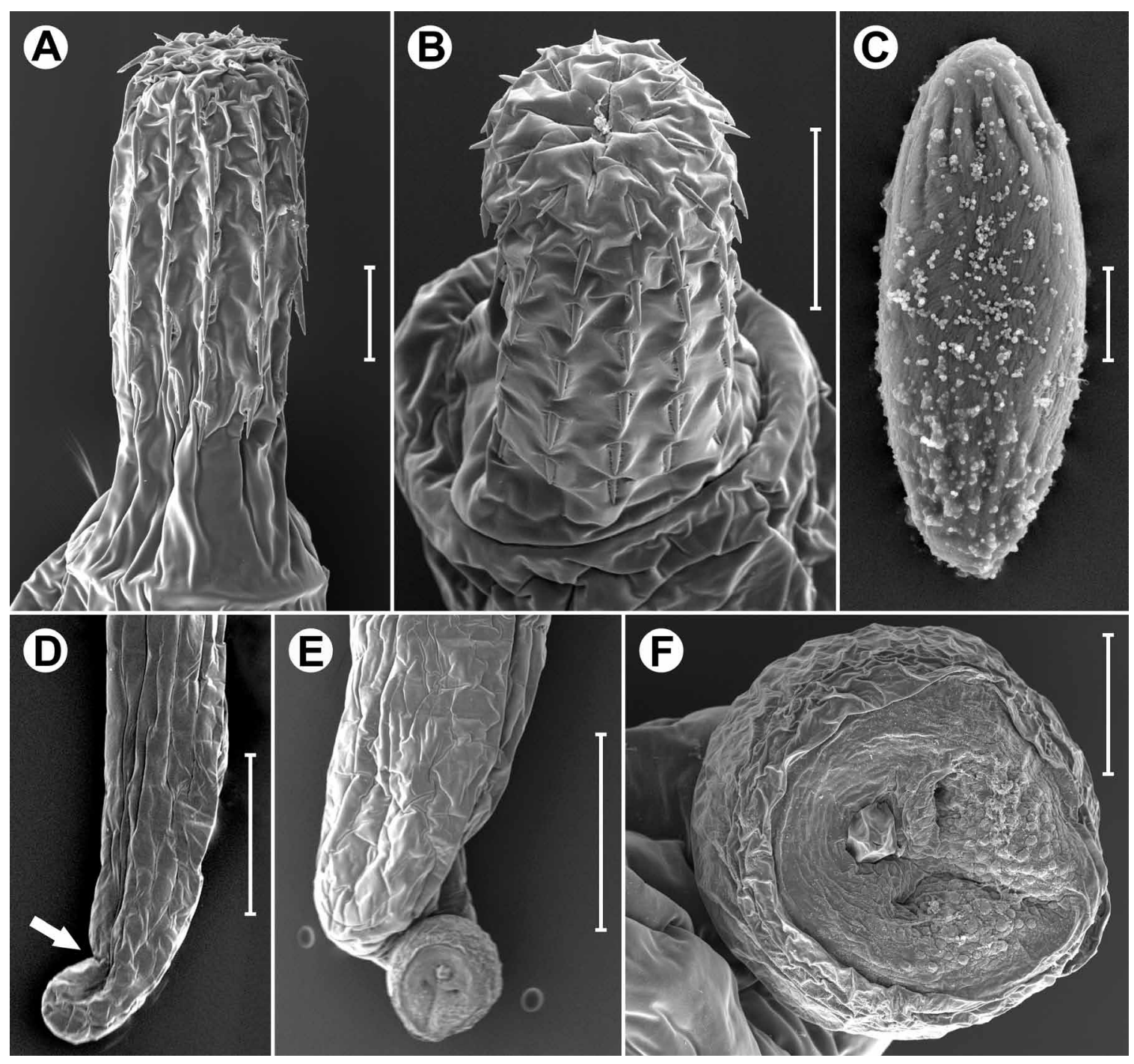

Fig 3. Pseudoacanthocephalus lutzi (Hamann, 1891) comb. n. from Rhinella arenarum, scanning electron micrographs. A - male proboscis; B - female proboscis; C - egg; D - female, showing the ventral sub-terminal genital pore (arrow); $\mathbf{E}$ - male, showing sigmoid-shaped posterior end and nearly terminal evaginated bursa; $\mathbf{F}$ - detail of bursa showing papillae and bursal pockets. Scale bars: $\mathrm{A}=100 \mu \mathrm{m} ; \mathrm{B}, \mathrm{F}=200 \mu \mathrm{m} ; \mathrm{C}=10 \mu \mathrm{m} ; \mathrm{D}, \mathrm{E}=1 \mathrm{~mm}$.

Material studied and localities: 36 males and 35 females from Rhinella arenarum collected in Luján City $\left(34^{\circ} 34^{\prime} \mathrm{S}, 59^{\circ} 06^{\prime} \mathrm{W}\right)$, Buenos Aires Province (June 2004 and August to December 2004) and from the Campus of the University $\left(34^{\circ} 36^{\prime} \mathrm{S}, 58^{\circ} 24^{\prime} \mathrm{W}\right)$, Buenos Aires City (June 2004, November 2007, June 2008 and February 2009), Argentina.

Material deposited: MACN-Pa No. 484/1-5 (3 males, 3 females) preserved in $70 \%$ ethanol, MACN-Pa No. 484/7-11 (2 complete males and 1 male as cross-sections, 3 complete females) mounted on slides; ZMB Vermes E7419 ( 1 male and 1 female) preserved in $70 \%$ ethanol, E7420 (1 male) and E7421 (1 female) mounted on slides.

Site of infection: Anterior and middle parts of the intestine.

Prevalence : $32 \%$ (17/53) (Luján City), 50\% (8/16) (Buenos Aires City).

Mean intensity of infection: 9(range 1-65) (Luján City), 8 (range 2-22) (Buenos Aires City).
Mean abundance: 2.9 (Luján City), 3.9 (Buenos Aires City).

Remarks. The examination of the type and new material of $A$. lutzi revealed three major diagnostic characters of Pseudoacanthocephalus, namely, cement glands in compact cluster (Figs. 1A, 2D, F, G), a nearly terminal male genital pore (Figs. 1A, 2D, 3E), and a ventral and sub-terminal female genital pore (Figs. 2A, 3D), all of which were absent in former descriptions (Hamann 1891, Meyer 1932, Hartwich 1956). The eggs floating in the fixative of the type specimens had a holoechinate acanthor, a conspicuous fibrillar coat of the second envelope (E2) and lacked polar prolongations of the third envelope (E3) as in those of from $R$. arenarum. The morphology of $A$. lutzi from $R$. arenarum and $R$. marina is consistent with the diagnosis of Pseudoacanthocephalus (see Petro- 
chenko 1956, Golvan 1969) and therefore it is transferred to this genus.

Pseudoacanthocephalus lutzi has a cylindrical trunk without spines; a proboscis armature of 14-18 longitudinal rows of 5-8 hooks each, with all roots formed by a posteriorly directed longitudinal spatulate sheet having a central rib, and an inconspicuous sheet directed anteriorly; a cerebral ganglion located near the base of the proboscis receptacle; digitiform to claviform lemnisci, as long as, or slightly shorter or slightly longer than the proboscis receptacle; post-equatorial oval testes arranged in tandem; a variable number $(4,5$ or 6 ) of cement glands; a bursa with 2 pockets and papillae; a sigmoid-shaped posterior end in males; an elliptical egg with fibrillar coat of E2 and without polar prolongations of E3, with a larval hook more robust and different in shape than the others.

The revision of the type material of $A$. saopaulensis Smales, 2007 ( 3 males, 4 females and parts of 2 females) from $R$. icterica permitted to re-evaluate the species. Among the specimens studied, only 2 females showed everted proboscis, with 15 longitudinal hook rows of 6-7 hooks each. In this species, Smales (2007) reported 16 longitudinal hook rows of 5-6 hooks each in males and of 6-7 hooks each in females, but his results fall in the range of those of $P$. lutzi (14-18 longitudinal hook rows of 5-8 hooks each). Furthermore, this author observed the presence of 6 cement glands arranged in a compact cluster, while the specimens examined in this study had 5 or 6 cement glands, this variation being also found in P. lutzi. Moreover, A. saopaulensis (see Smales 2007, fig. 4) shares with $P$. lutzi a sigmoid-shaped male posterior end (Fig. 3E). The cerebral ganglion is near the base of the proboscis receptacle rather than at its base. The eggs found in the fixative medium of $A$. saopaulensis had a fibrillar coat of E2, lacked polar prolongations of E3 and contained a holoechinate acanthor (Fig. 4B), as those of $P$. lutzi (Figs. 1C, 2E). The size of the holoechinate acanthor of $A$. saopaulensis 48-62 (55, $\mathrm{n}=10)$ long by 18-29 $(22, \mathrm{n}=10)$ wide, is very similar to that of $P$. lutzi. In the original description of Smales (2007), the eggs of A. saopaulensis were slightly larger 89-102.3 (95.4) than those measured in the type material of P. lutzi 82-93 (87) (present study). However, Hamann (1891) reported eggs measuring 100. The differences between A. saopaulensis and $P$. lutzi do not justify the retention of the former. Consequently, A. saopaulensis is considered conspecific with P. lutzi.

Pseudoacanthocephalus lutzi shows variability in body length, number of hook rows and hooks per row, these features being of limited taxonomic value because they seem to be related to the host species. This variability among specimens from different host were also noted by Amin (1984) and Amin et al. (2008) in Acanthocephalus dirus (Van Cleave, 1931) and Pseudoacanthocephalus nguyenthileae Amin, Van Ha et Heckmann, 2008, both of which parasitize a wide range of hosts.
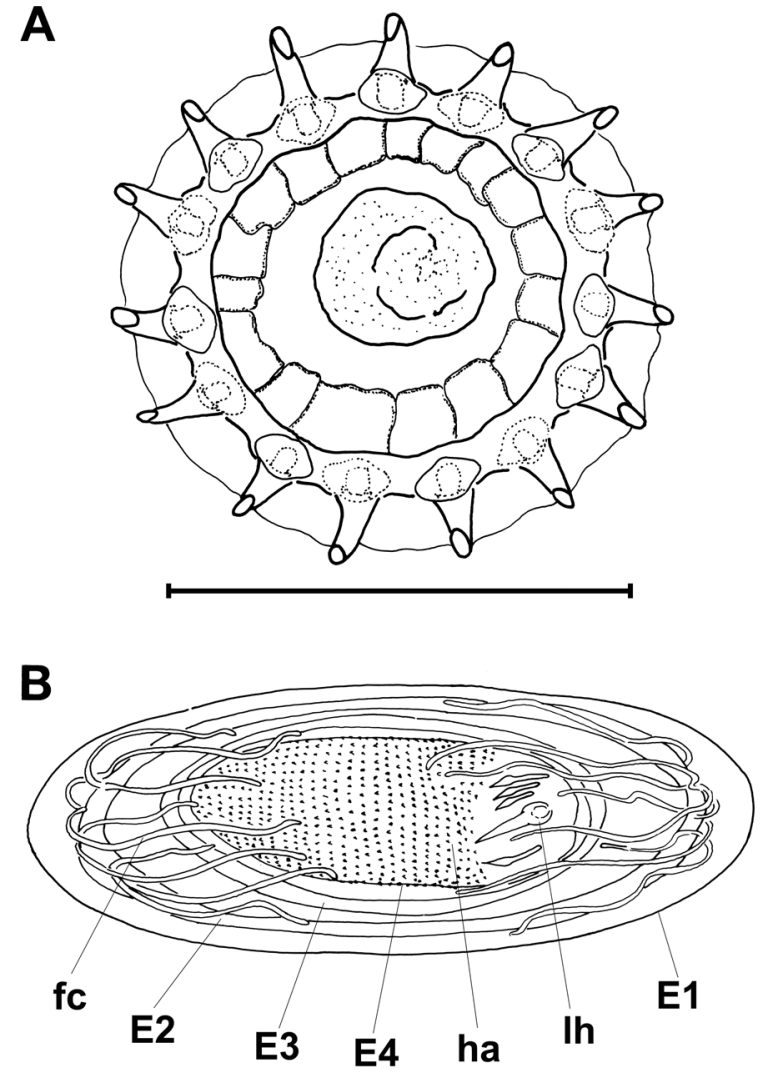

Fig. 4. Pseudoacanthocephalus lutzi (Hamann, 1891) comb. n. A - cross-section at the proboscis level of a specimen parasitizing Rhinella arenarum; $\mathbf{B}$ - egg from a specimen (paratype INVE 38665) parasitizing Rhinella icterica. Abbreviations: E1 - first envelope; E2 - second envelope; E3 - third envelope; $\mathrm{E} 4$ - fourth envelope adhered to holoechinate acanthor; fc - fibrillar coat; ha - holoechinate acanthor; $\mathrm{lh}$ - larval hooks. Scale bars: $\mathrm{A}=300 \mu \mathrm{m} ; \mathrm{B}=50 \mu \mathrm{m}$.

The study of a paratype of $A$. caspanensis Fernández et Ibarra Vidal, 1992 allowed to confirm that it possesses all the characteristics mentioned above for Pseudoacanthocephalus, such as a variable number of cement glands, 5 (present study) or 6 (Fernández and Ibarra Vidal 1992); a sigmoid-shaped male posterior end (see Fernández and Ibarra Vidal 1992, fig. 9); and an elliptical egg with fibrillar coat of E2 and without polar prolongations of E3 (see Fernández and Ibarra Vidal 1992, fig. 6 ). Fernández and Ibarra Vidal (1992) made no mention of the presence of a holoechinate acanthor, but it is apparently illustrated in their fig. 6. Thus, P. caspanensis differs from P. lutzi by having a pair of lemnisci notably longer than the proboscis receptacle, all hook roots without an anterior sheet, and a slightly smaller egg ( $60-72$ by $22-26$ vs. $82-93$ by 29-42, respectively). In addition, the fact that the distribution of $R$. spinulosa, the host of $P$. caspanensis, is restricted to the Andean mountains of South America (Frost 2009) suggests geographic isolation of the host and para- 
site. In this regard, it is surprising that Smales (2007) recorded P. caspanensis from amphibians in Paraguay, with no Andean distribution (Frost 2009).

\section{DISCUSSION}

The reallocation of Acanthocephalus lutzi to the genus Pseudoacanthocephalus Petrochenko, 1956 (see Petrochenko 1956, Golvan 1969, Amin et al. 2008) is proposed based on the study of type material from Rhinella marina and new material from Rhinella arenarum (reported previously from Argentina by Lajmanovich and Martínez de Ferrato 1995). Likewise, Acanthocephalus saopaulensis from Rhinella icterica is synonymised with $P$. lutzi, and the characters of the type material of Acanthocephalus caspanensis from $R$. spinulosa support the reassignment of this species to Pseudoacanthocephalus.

Tantaleán (1976) and Tantaleán et al. (2005) reported A. lutzi from Rhinella arequipensis (Vellard), R. limensis (Werner), R. marina and R. spinulosa (syns. Bufo flavolineatus Cei and B. trifolium Tschudi; see Frost 2009) from Peru, with no comments on their morphology. The results obtained in the present study indicate the need for a taxonomic revision of these acanthocephalans.

Machado-Filho (1970) described Acanthocephalus correalimai from females parasitizing $R$. marina in Brazil. This author justifies the creation of the new species based on a slender proboscis and eggs slightly smaller than those of Pseudoacanthocephalus lutzi. Later, Lent and Portes Santos (1989) confirmed that the MachadoFilho's material had a slender proboscis. However, it is worthy to mention that the specimens had been mounted in Canada balsam (Dr. M. Knoff, Curator of CHIOC, Brazil; pers. comm.); mounting requires dehydration, which may have caused the distortion of the shape of the proboscis. The egg of $A$. correalimai has a fibrillar coat and lacks polar prolongations (see Machado-Filho 1970, fig. 2) and the female has a sub-terminal genital pore (see Machado-Filho 1970; fig. 3). Consequently, it is proposed that $A$. correalimai be retained provisionally in the genus Acanthocephalus until studying the males. It is worthwhile to highlight that $A$. correalimai and $P$. lutzi share the same type host, i.e., $R$. marina.

Acanthocephalus acutispinus was briefly described by Machado-Filho (1968) from Hylodes lateristrigatus (Baumann) (syn. Elosia lateristrigatus Baumann). Since the species was characterised only from females, it should be retained provisionally in the genus Acanthocephalus.

Acanthocephalus ula Lent et Portes Santos, 1989, parasite of Atelopus oxyrhynchus Boulanger from Venezuela, is a problematic species. It not only shows the distinctive characteristics of the genus Acanthocephalus, i.e. non-clustered cement glands (see Lent and Portes Santos 1989; figs. 5, 7) and an ellipsoidal egg, with polar prolongations (see Lent and Portes Santos 1989; fig. 2), but it also shares features with Pseudoacanthocephalus, i.e., a nearly terminal male genital pore (see Lent and Portes Santos 1989; fig. 5), a sigmoid-shaped male terminal end (see Lent and Portes Santos 1989; fig. 7), and a sub-terminal female genital pore (see Lent and Portes Santos 1989; fig.1). No taxonomic action is taken for this species until new material is studied.

Bursey and Goldberg (2007) reallocated A. lutzi (Hamann, 1891) to Anuracanthorhynchus Bursey, Vrcibradic, Hatano et Rocha, 2006, but in the light of the present study this taxonomic action is not acceptable.

Petrochenko (1956) in his diagnosis of Pseudoacanthocephalus states that the holoechinate acanthor is associated with terrestrial amphibian hosts. However, this larval type was also found in acanthocephalans parasitizing aquatic hosts, e.g., Acanthocephalus dirus (Van Cleave, 1931) (syn. A. jacksoni) from freshwater fish (West 1964).

Nikishin (2001) reviewed the organisation of the embryonic envelopes in different acanthocephalan classes. He noted differences in the third envelope (E3) between the Palaeacanthocephala (parasites of aquatic or semiaquatic hosts) and the Archiacanthocephala (parasites of terrestrial hosts); the E3 is absent in the former, whereas it reaches maximum complexity in the latter, showing 4 layers: E3a, b, c, and d. The E3d of the Archiacanthocephala is very thick, and Nikishin (2001) speculated that it may preserve the viability of embryonic larvae under terrestrial conditions (see Nikishin 2001; fig. 4).

Instead, the fibrillar coat of the second envelope (E2) of the egg is a better indicator of the lifestyle of the host, or rather of the life cycle of the parasite. When the eggs are in the water, they lose their first envelope (E1) and the filaments of the fibrillar coat concentrated at the poles get entangled with submerged algae and plants, where they are most likely to be eaten by an aquatic intermediate host (Barger and Nickol 1998, Nikishin 2001). Thus, the morphology of the egg may be indicative of the first intermediate host in the life cycle of acanthocephalans, which is useful to distinguish between species rather than genera.

An ecological aspect of the amphibian host, particularly whether it feeds on terrestrial or aquatic arthropods, has been used as a major character in the diagnosis of Pseudoacanthocephalus. However, numerous South American Rhinella spp. may not show clear-cut preferences for feeding habitats. They are regarded as generalist and opportunist feeders, with a wide trophic spectrum depending on the environment they live in, seasonality and prey availability (Zug and Zug 1979, Lajmanovich 1994, Evans and Lampo 1996, Attademo et al. 2005, 2007, Gutiérrez et al. 2008, Sabagh and Carvalho-e-Silva 2008, Naya et al. 2009).

Rhinella marina, the type host of Pseudoacanthocephalus lutzi, is a native toad of Central and South America. It lives in a wide variety of habitats including arid and semiarid areas, savannah woodlands (with some areas subject to seasonal floods), forests and scrub lands (Evans and 
Lampo 1996). This species mainly feeds on terrestrial insects such as ants and beetles (Weber 1938), but it also is an opportunist with a highly diversified diet reflecting the regional and seasonal abundance of prey (Zug and Zug 1979). Evans and Lampo (1996), who studied the diet of $R$. marina in different habitats in Venezuela, found that aquatic Odonata larvae were major prey items in arid areas, indicating that $R$. marina may obtain food from the few permanent water bodies. This suggests that aquatic insects may act as intermediate hosts for $P$. lutzi.

In sum, $P$. lutzi seems to have a semi-aquatic life cycle because its egg has a fibrillar coat and lacks the E3d layer (typical of the Archiacanthocephala), and because the diet of its host includes aquatic insects.

This study indicates the need to re-evaluate the South American species Acanthocephalus acutispinus, A. correalimai and $A$. ula by examining type material and new material comprising both males and females. These should be properly fixed to obtain complete relaxation leading to accurate descriptions and high-quality figures. It is also recommended to clear specimens in lactophenol or beechwood creosote, which allows the rotation of the specimen during examination. The use of scanning electron microscopy is also of particular interest, as well as a detailed description of the external morphology based on micrographs.

Acknowledgements. The authors thank Dr. B. Neuhaus, curator of the Museum für Naturkunde, Zentralinstitut der HumboldtUniversität, Berlin, Germany; Dr. Jorge N. Artigas, curator of the Museo Zoológico de la Universidad de Concepción, Chile; Dr. A. de Chambrier, assistant curator of the Invertebrate Collection, Museum of Natural History, Geneva, Switzerland, for loan of type material; and Dr. M. Knoff, curator of the Helminthological Collection, Instituto Oswaldo Cruz, Rio de Janeiro, Brazil, for providing information on deposited specimens. Special thanks are also due to Dr. Omar Amin, Dr. R. Lajmanovich, Dr. V.P. Nikishin, Dr. C. Portes Santos, and Dr. M. Tantaleán for providing us with their own papers. Special thanks are also due to the two anonymous referees for their valuable comments that helped to improve this manuscript. This research was supported by CONICET (Grant PIP No. 5974), ANPCyT (Proj. BID 1728 OC-AR PICT No. 825) and Universidad de Buenos Aires (Grants UBACyT-X443 and X453).

\section{REFERENCES}

Amin O.M. 1984: Variability and redescription of Acanthocephalus dirus (Acanthocephala: Echinorhynchidae) from freshwater fishes in North America. Proc. Helminthol. Soc. Wash. 51: 225-237.

Amin O.M. 1985: Classification. In: D.W.T. Crompton and B.B. Nickol (Eds.), Biology of the Acanthocephala. Cambridge University Press, Cambridge, UK, pp. 27-72.

Amin O.M., Ha N.V., Heckmann R.A. 2008: New and already known acanthocephalans from amphibians and reptiles in Vietnam, with keys to species of Pseudoacanthocephalus Petrochenko, 1956 (Echinorhynchidae) and Sphaerechinorhynchus Johnston and Deland, 1929 (Plagiorhynchidae). J. Parasitol. 94: 181-189.

Attademo A.M., Cejas W., Peltzer P.M., Lajmanovich R.C. 2007: Phenology in the diet of Chaunus arenarum (Anura: Bufonidae) in a soybean field of Córdoba province, Argentina. Rev. Esp. Herpetol. 21: 41-48.

Attademo A.M., Peltzer P.M., Lajmanovich R.C. 2005: Amphibians occurring in soybean and implications for biological control in Argentina. Agric. Ecosyst. Environ. 106: 389-394.

Barger M.A., Nickol B.B. 1998: Structure of Leptorhynchoides thecatus and Pomphorhynchus bulbocolli (Acanthocephala) eggs in habitat partitioning and transmission. J. Parasitol. 84: 534-537.

Bush A.O., Lafferty K.D., Lotz J.M., Shostak A.W. 1997: Parasitology meets ecology on its own terms: Margolis et al. revisited. J. Parasitol. 83: 575-583.

Bursey S.R., Goldberg S.R. 2007: New species of Hedruris (Nematoda: Hedruridae), Anuracanthorhynchus lutzi (Hamann, 1891) n. comb. and other helminths in Lithobates warszewitschii (Anura: Ranidae) from Costa Rica. Carib. J. Sci. 43: 1-10.

Cordero E.-H. 1933: Sur quelques acanthocéphales de l'Amerique Méridionale, I. Ann. Parasitol. 11: 271-279.

Evans M., Lampo M. 1996: Diet of Bufo marinus in Venezuela. J. Herpetol. 30: 73-76.

Fernández J.C., Ibarra Vidal H.G. 1992: Acanthocephalus caspanensis n. sp. (Acanthocephala. Echinorhynchidae) parásito de Bufo spinulosus Wiegmann en el Altiplano Chileno. Acta Zool. Lilloana 41: 207-213.

Frost D.R. 2009: Amphibian Species of the World: an Online Reference. Version 5.3 (12 February, 2009). Electronic Database accessible at http://research.amnh.org/herpetology/amphibia/. American Museum of Natural History, New York, USA.

Frost D.R., Grant T., Faivovich J., Bain R.H., HaAs A., Haddad C.F.B., De Sá R.O., Channing A., Wilkinson M., Donellan S.C., Raxworthy C.J., Campbell J.A., Blotto B.L., Moler P., Drewes R.C., Nussbaum R.A., Lynch J.D., Green D.M., Wheeler W.C. 2006: The amphibian tree of life. Bull. Am. Mus. Nat. Hist. 297: 1-370.

Golvan Y.J. 1969: Systématique des acanthocéphales (Acanthocephala Rudolphi 1801). Première partie: L'ordre des Palaeacanthocephala Meyer 1931, première fascicule: la super-famille des Echinorhynchoidea (Cobbold 1876) Golvan et Houin 1963. Mem. Mus. Natl. Hist. Nat., Ser. A, Zool., 57: 1-373.

Golvan Y.J. 1994: Nomenclature of the Acanthocephala. Res. Rev. Parasitol. 54: 135-205.

Gutiérrez C., Attademo A., Guerrero S., Peltzer P., LajMANOVICH R. 2005: Physalaemus biligonigerus (False-eyed Frog) endoparasites. Herpetol. Rev. 36: 161-162.

Gutiérrez N., Méndez M.A., Sallaberry M. 2008: Hábitos alimentarios de Bufo spinulosus Wiegmann, 1835 (Anura: Bufonidae) en la localidad de Farellones (Región Metropolitana). Bol. Mus. Nac. Hist. Nat., Chile, 57: 141-148.

Hamann O. 1891: Monographie der Acanthocephalen, I.Teil. Jenaische Z. Naturwiss. 25: 113-231.

Hartwich G. 1956: Südamerikanische Acanthocephalen aus der Zoologischen Sammlung des Bayerischen Staates. Zool. Anz. 156: 299-308.

Lajmanovich R.C. 1994: Hábitos alimentarios de Bufo paracnemis (Amphibia, Bufonidae) en el Paraná medio, Argentina. Rev. Hydrobiol. Trop. 27: 107-112. 
Lajmanovich R.C., Martínez de Ferrato A. 1995: Acanthocephalus lutzi (Hamann, 1891) parásito de Bufo arenarum en el Río Paraná, Argentina. Rev. Asoc. Cienc. Nat. Litoral 26: 19-23.

Langeron M. 1949: Précis de Microscopie. 7th Edition. Masson \& Cie, Paris, 429 pp.

Lent H., Portes Santos C. 1989: Acanthocephalus ula n. sp. (Acanthocephala, Echinorhynchidae) and Schulzia usu n. sp. (Nematoda, Molineidae) described from Atelopus oxyrhynchus (Amphibia) from Venezuela. Rev. Brasil. Biol. 49: 1085-1091.

Machado-Filho D.A. 1968. Nova espécie do gênero Acanthocephalus Koelreuther, 1771 (Acanthocephala, Echinorhynchidae). Atas Soc. Biol. Rio de J. 12: 53-54.

Machado-Filho D.A. 1970: Nova espécie do gênero Acanthocephalus Koelreuther, 1771 (Acanthocephala: Echinorhynchidae). Atas Soc. Biol. Rio de J. 13: 53-54.

MARChAND B. 1984: A comparative ultrastructural study of the shell surrounding the mature acanthor larvae of 13 acanthocephalan species. J. Parasitol. 70: 886-901.

Meyer A.1932: Acanthocephala. In: Bronn's Klass. u. Ordn. d. Tierreichs. Vol. 4, Abt. 2, Buch 2, Lief. 1. Akademische Verlagsgesellschaft, Leipzig, $332 \mathrm{pp}$.

Naya D.E., Veloso C., Bozinovic F. 2009: Gut size variation among Bufo spinulosus populations along an altitudinal (and dietary) gradient. Ann. Zool. Fenn. 46: 16-20.

Nikishin V.P. 2001: The structure and development of embryonic envelopes in acanthocephalans. Biol. Bull. 28: 40-53.

Received 8 September 2009
Petrochenko V.I. 1956: Acanthocephala of Domestic and Wild Animals. Vol. 1. Izdatel'stvo Akademii Nauk SSSR, Moscow. (In Russian. English Translation by Israel Program for Scientific Translation, Jerusalem, Israel, 1971, 465 pp.)

Sabagh L.T., Carvalho-e-Silva A.M.P.T. 2008: Feeding overlap in two sympatric species of Rhinella (Anura: Bufonidae) of the Atlantic rain forest. Rev. Bras. Zool. 25: 247-253.

Smales L.R. 2005: Acanthocephalans from some frogs and toads (Anura) and (Squamata) from Tanzania with the description of a new species. J. Parasitol. 91: 1459-1464.

Smales L.R. 2007: Acanthocephala in amphibians (Anura) and reptiles (Squamata) from Brazil and Paraguay with description of a new species. J. Parasitol. 93: 392-398.

TANTALEÁN M. 1976: Contribución al conocimiento de los helmintos de vertebrados del Perú. Biota 10: 437-443.

Tantaleán M., Sánchez L., Gómez L., Huiza A. 2005: Acantocéfalos del Perú. Rev. Peru. Biol. 12: 83-92.

Weber N.H. 1938: The food of giant toad, Bufo marinus (L.), in Trinidad and British Guiana with special reference to the ants. Ann. Entomol. Soc. Am. 31: 499-503.

WEST A.J. 1964: The acanthor membranes of two species of Acanthocephala. J. Parasitol. 50: 731-734.

Yamaguti S. 1963: Systema Helminthum. Vol. 5, Acanthocephala. Wiley Interscience, New York, $423 \mathrm{pp}$.

Zug G.R., Zug P.B. 1979: The marine toad, Bufo marinus: a natural history resume of native populations. Smithson. Contrib. Zool. 28: 1-58.

Accepted 12 November 2009 